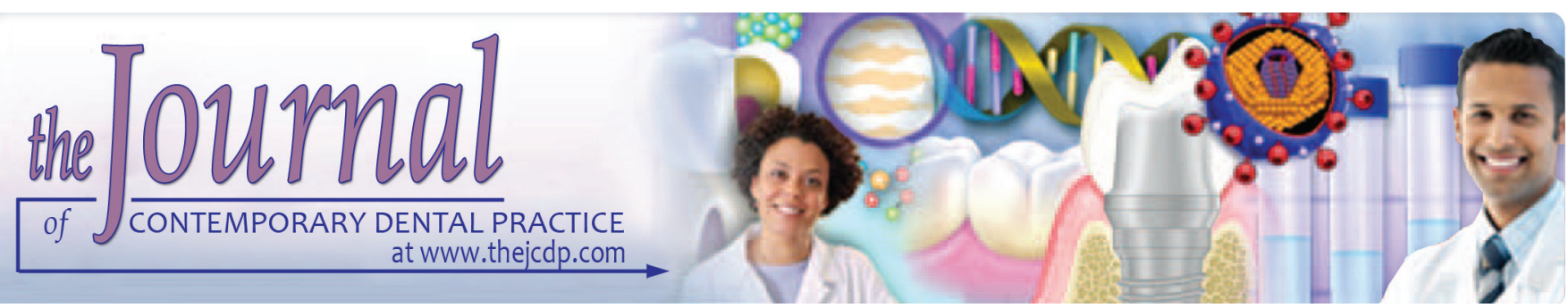

\title{
Parental Presence/Absence in the Dental Operatory as a Behavior Management Technique: A Review and Modified View
}

${ }^{1}$ Hicham Riba, ${ }^{2}$ Asma Al-Shahrani, ${ }^{3}$ Hayat Al-Ghutaimel, ${ }^{4}$ Adel Al-Otaibi, ${ }^{5}$ Salim Al-Kahtani

\begin{abstract}
Introduction: Parental presence/absence in the dental operatory (also called: Parent-in-parent-out technique) is an extremely controversial aspect of the nonpharmacological BMTs. Historically, dentists used to exclude parents from dental operatory to avoid their interference with the dentist's aptitude to build a rapport and relationship with the child, hence increasing the child management problems by disrupting treatment and making the dentist unfocused and uncomfortable.
\end{abstract}

Aim: The purpose of this article is to review and emphasize on the importance of parental presence/absence in the dental operatory, especially in a certain age group, as a behavior management technique (BMT) in pediatric dentistry, and to present a modified view of this technique.

Results: This article reviews the current literature concerning behavior management in pediatric dentistry. It includes a medline database search and review of the comprehensive textbooks in pediatric dentistry. Some recommendations were based on the opinions of experienced researchers and clinicians.

Conclusion: Parent-in-parent-out technique in dental operatory is advocated to gain emotional support and avoid the effect of traumatic separation, especially in younger children or special health-care needs patients.

Clinical significance: The parent-in-parent-out technique in dental operatory is underused, or misused. This article clarifies the proper use of this technique along with a minor modification to it to make it more effective on young apprehensive dental patients.

\footnotetext{
${ }^{1-5}$ Department of Preventive Dental Science, King Saud bin Abdulaziz University for Health Sciences, Riyadh, Kingdom of Saudi Arabia

Corresponding Author: Hicham Riba, Department of Preventive Dental Science, King Saud bin Abdulaziz University for Health Sciences, Riyadh, Kingdom of Saudi Arabia, Phone: +0016302295050, e-mail: ribah@ksau-hs.edu.sa
}

Keywords: Behavior management, Dental operatory, Parental absence, Parental presence, Pediatric dentistry.

How to cite this article: Riba $\mathrm{H}, \mathrm{Al}-\mathrm{Sh}$ ahrani $\mathrm{A}, \mathrm{Al}-\mathrm{G}$-Gutaimel $\mathrm{H}$, Al-Otaibi A, Al-Kahtani S. Parental Presence/Absence in the Dental Operatory as a Behavior Management Technique: A Review and Modified View. J Contemp Dent Pract 2018;19(2):237-241

Source of support: Nil

Conflict of interest: None

\section{INTRODUCTION}

Children usually experience reactions of strong fear and acute anxiety when visiting the dental office. In response to their fear and anxiety about dental procedures, they more likely respond to their feelings and exhibit a wide range of negative attitudes and behaviors. ${ }^{1}$ Therefore, a diversity of BMTs is used for children during the dental procedures to alleviate their fear and anxiety, promote their positive attitude, deliver good-quality dental care, establish communication, and build trust relationship between the child and the dental team. ${ }^{2}$

Behavior management is the science and art of adjusting a negative behavior and developing new behaviors that will help the child cope with and withstand the delivered dental procedures. ${ }^{3-5}$ The BMTs are considered essential in pediatric dentistry. Without such a skill, dentists would not be able to deliver appropriate and safe treatment. ${ }^{3-7}$

In 1895, McElroy wrote: "Although the operative dentistry may be perfect, the appointment is a failure if the child departs in tears". ${ }^{8}$ This was considered the first base mentioned in the pediatric dental literature to measure success or failure of a child's dental visit. ${ }^{2}$ Later, it has led to the definition of behavior modification as (the attempt to alter human behavior and emotion in 
a beneficial manner and in accordance with the laws of learning theory). ${ }^{9}$ The BMT includes nonpharmacological and pharmacological techniques. The decision on which BMT is to be used depends on the patient's need and condition, as well as dentist's preference and skills and the approval of the parents. ${ }^{3}$ The BMTs can be also divided into basic and advanced techniques according to the American Academy of Pediatric Dentistry. ${ }^{3}$ Basic BMTs include a group of techniques that are known as communication and communicative guidance, such as tell-show-do, positive reinforcement, distraction, voice control, nonverbal communication, and parental presence/absence. ${ }^{10}$ Advanced BMTs include protective restraint, sedation, and general anesthesia, which require informed consent from the parents or legal guardian. ${ }^{10}$ The BMTs should be learned and developed by all staff in the pediatric dental clinic, starting with the receptionist, who welcomes the parents and their child and ending with the pediatric dentist, who will perform the treatment. 6,7

Parental presence/absence is one of the nonpharmacological BMTs. In this technique, the parental presence is used as a factor to manage the child's negative behavior. Whether a parent should be present or not during a dental appointment is a matter of controversy among pediatric dentists because complete parental separation might cause emotional trauma to the child. ${ }^{11}$ In addition to that, some parents would not agree on their children being out of sight, which will complicate this technique.

The purpose of this article is to review and emphasize on the importance of parental presence/absence in the dental operatory as a BMT in pediatric dentistry and present a modified view of this technique to gain the child's cooperation without causing traumatic impact as a result of the complete parental separation.

\section{MATERIALS AND METHODS}

This article reviews the current literature concerning behavior management in pediatric dentistry. It includes a medline database search using key terms: "Behavior management", "parent presence in the operatory", "attitude of the parent toward behavior management", "attitude of the dentist toward parental separation", and "attitude of the child toward parental separation". Articles were evaluated by title and/or abstract and relevance to behavior management in pediatric dentistry. Totally, 29 citations were selected by this method and by the references within the chosen articles. A review of the comprehensive textbooks on pediatric dentistry was done. Some recommendations were based on the opinions of experienced researchers and clinicians.

\section{DISCUSSION}

Good communication with the parents, including an explanation of the diagnosis, proposed treatment, outcome, and different BMTs that can be used, creates a very favorable environment, as the parents become more relaxed when they are aware of their child's situation. This, in turn, most likely will affect the child positively as he/she becomes relaxed too. ${ }^{5,12}$ However, in some cases, parents could affect the child's behavior negatively. ${ }^{13}$

Parental presence/absence in the operatory is an extremely controversial aspect of BMTs. Historically, dentists used to exclude parents from the dental operatory to avoid their interference with the dentist's ability to build a rapport and relationship with the child, hence increasing child's management problems, disrupting treatment, and making the dentist unfocused and uncomfortable. ${ }^{14}$

The dentist is the one to determine whether the presence of a parent during a procedure would have a positive or negative impact, ${ }^{4,15}$ and according to that, he/she could ask the parent to leave the operatory, when needed. This is considered to be one of the BMTs known as parental presence/absence. ${ }^{16-18}$

Research has found that parents with a negative attitude toward dentistry are most likely to convey their attitude to their children. 2,12,13 The correlation between parental anxiety and child negative behavior has been documented in several studies. ${ }^{2,13,19}$ However, Frankl et $\mathrm{al}^{12}$ and several other authors reported an increase in the child's cooperation relative to parental presence in the operatory during a dental examination and treatment. Lewis and $\mathrm{Law}^{20}$ reported no differences in the child behavior whether the parent was present or absent.

Several studies have been attempted to investigate the attitude of parents toward BMTs. ${ }^{10,14,21}$ Those studies concluded that most of the parents prefer to accompany their children in the dental operatory. ${ }^{14,21}$ A dentist should understand that some parents would not agree on being separated from their children as they feel that they should protect them in the dental clinic. ${ }^{3,22,23}$ Parents' desire to be present/absent during the treatment and whether they were actually present/absent in the dental clinic would affect their satisfaction and response toward the dentist and the provided treatment. ${ }^{24}$ In 2009, Abushal and Adenubi concluded from their study that Saudi parents classify parents' separation among the least acceptable BMTs along with voice control, hand over mouth, and physical restraints. ${ }^{21}$ In a study done by Kim et al, ${ }^{24}$ it was found that the younger the child is and the older the parents are, the more the parents wanted to be present in the dental clinic. Another study concluded that parents of children with special needs were less accepting to different BMTs, compared with parents of healthy children. ${ }^{7}$ 
Some authors recommended an interesting technique; rather than separating a child from his/her parent, which can often be traumatic, the parent is separated from the child. In other words, the dental assistant joins the child in the reception area and then leads him/her to the operatory to see the equipment, be photographed, radiographed, and prepared, while the parent is invited to a private office to discuss the child's history and dental status. ${ }^{12,25}$ However, the age factor is the key of success for this technique. Some advocate using this technique between the ages of 36 and 40 months, ${ }^{25}$ while others 42 to 49 months. ${ }^{12}$ Children 50 to 60 months of age, however, do not exhibit significant differences in behavior due to the parents' presence or absence.

\section{Parental Presence/Absence Technique Protocol}

It is one of the BMTs, which, generally, aids in gaining the child's cooperation to deliver the treatment in an effective and efficient manner. Parental presence in the operatory could decrease the compounding effect of traumatic separation, offer emotional support for the child, ${ }^{26}$ and aid in communication. ${ }^{27}$

The steps taken when using this technique are as follows:

- A preappointment letter or message is sent to the parents, to briefly explain the work that will be done during the first dental visit and the BMTs, which might be used during the first and following visits, including, but not limited to the parent-in-parent-out technique.

- A videotape to illustrate different BMTs is played to the parents after collecting the necessary patient's information on their arrival. Playing such a video recording has been found to be very helpful. ${ }^{26}$ Another video recording is played to the child to prepare him/ her for the dental visit. Such a recording is considered as a modeling tool. ${ }^{28,29}$

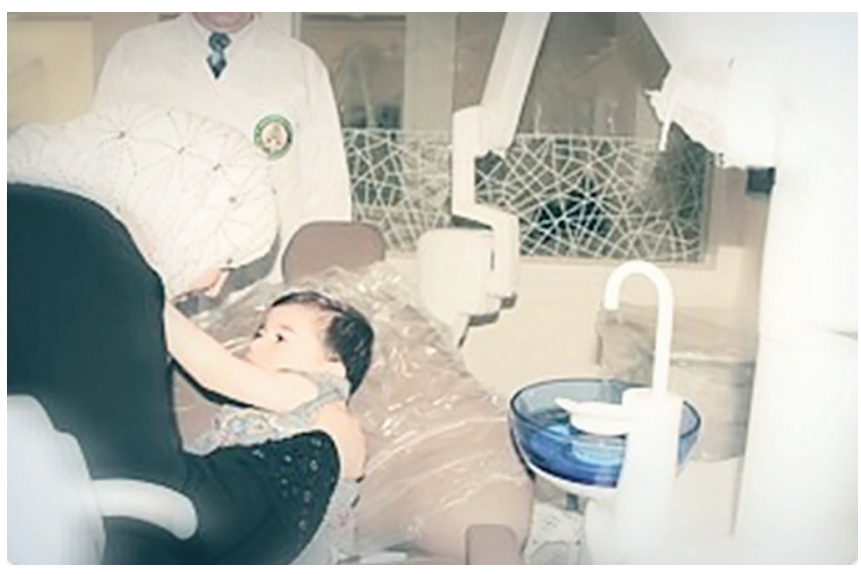

Fig. 1: Child is noncooperative and attached to his mother
- When the parents are in the operatory, they are not allowed to interfere with the procedure after they have approved and consented to the proposed treatment. Furthermore, the parents should be prepared to leave the dental operatory if the youngster does not cooperate. This agreement between the dentist and the parents needs to be made before the child is seated in the dental chair, and it is important that the child knows about the agreement. ${ }^{25}$

- Children between 36 and 49 months of age are good candidates when this technique is used. ${ }^{12,25}$

- The child should understand the seriousness of having the parents leave, if necessary. On the promise of the child to cease the uncooperative behavior, the parents are allowed to return to the treatment room. If the child resumes the unwanted behavior, the parents are asked again to leave. This is repeated until the child's cooperation is gained. If the child is overly anxious, it is preferable to use other techniques.

\section{A New Modification of the Parental Presence/Absence Technique}

The new view, which was developed by the first author, is to use a wall or a small transparent barrier next to the dental chair. The following will explain this modification:

- The parent is seated near the child without disrupting the interaction between the dentist and the child.

- If the child continues to be noncooperative, the parent is asked to stand behind the wall. This change in the surrounding area will have an effect on the child and make him/her think about the seriousness of losing the privilege of being next to the parent. The modification in this technique may prevent the disruptive behavior that might occur due to the emotional trauma caused by the total absence of the parent when directed to stay in the waiting area, instead of staying behind the wall (Figs 1 to 3).

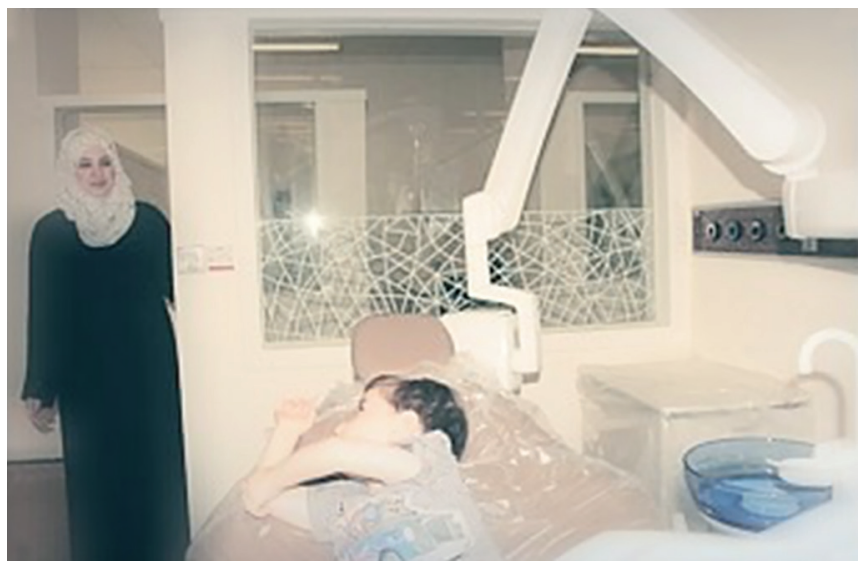

Fig. 2: The mother is asked to step backward as the child continues the disruptive behavior 


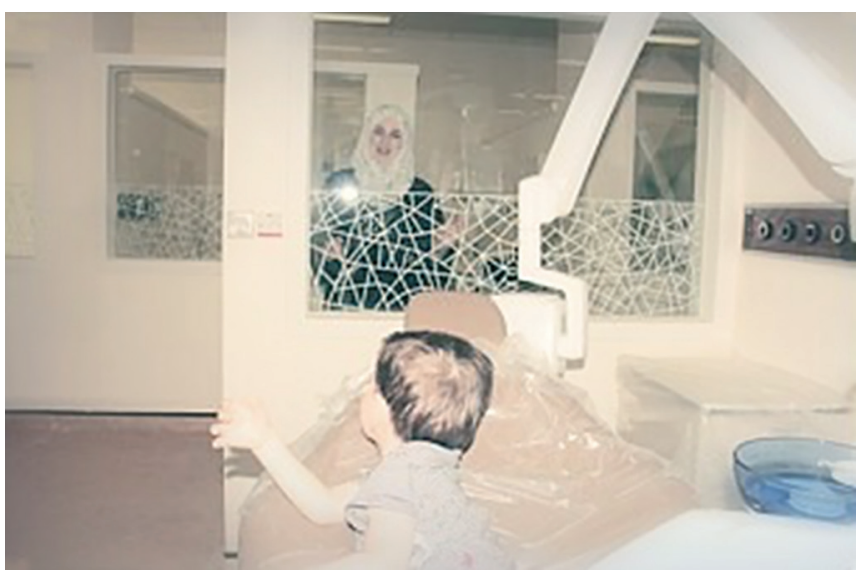

Fig. 3: The mother was told to depart to a further area, behind the transparent barrier, as the child is still being uncooperative

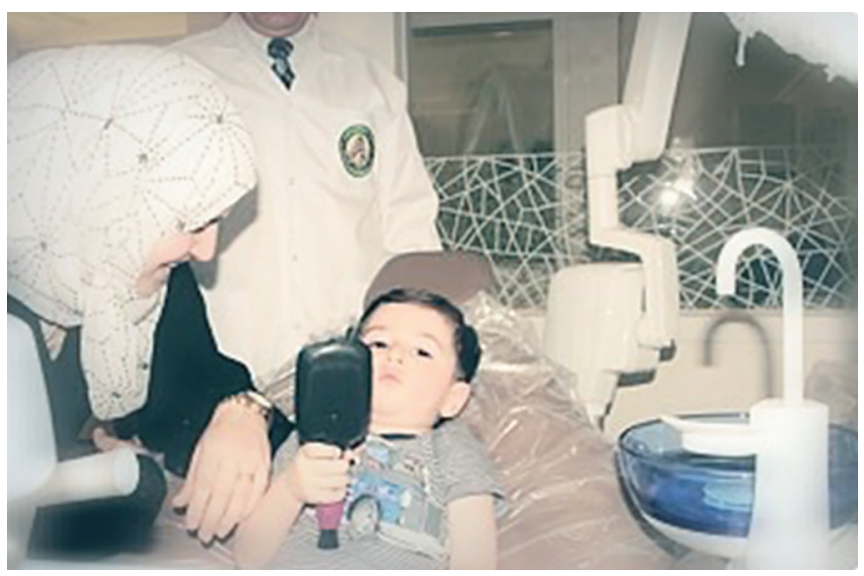

Fig. 5: According to the child's promise, the mother is allowed to return to the operatory. Note the mirror is used to deliver the (tell-show-do) technique

- If the child continues the disruptive behavior, the parent is asked to depart to the waiting area.

- According to the child's promise, the parent is allowed to return to the operatory. This is repeated until an acceptable behavior is obtained and the child is able to communicate and cooperate (Figs 4 and 5). However, if the disruptive behavior is continued, other BMTs are to be used (e.g., restraint, sedation, etc.).

\section{CONCLUSION}

Parental presence in the dental operatory is advocated to gain emotional support and avoid the effect of the traumatic separation, especially in younger ages and in patients with special health care needs. However, in the case of a noncooperative child, a modification of the technique can help the dentist gain the child's cooperation without traumatizing him/her emotionally. Parent-in-parent-out technique is used along with additional BMTs, such as modeling, positive reinforcement, and other techniques.

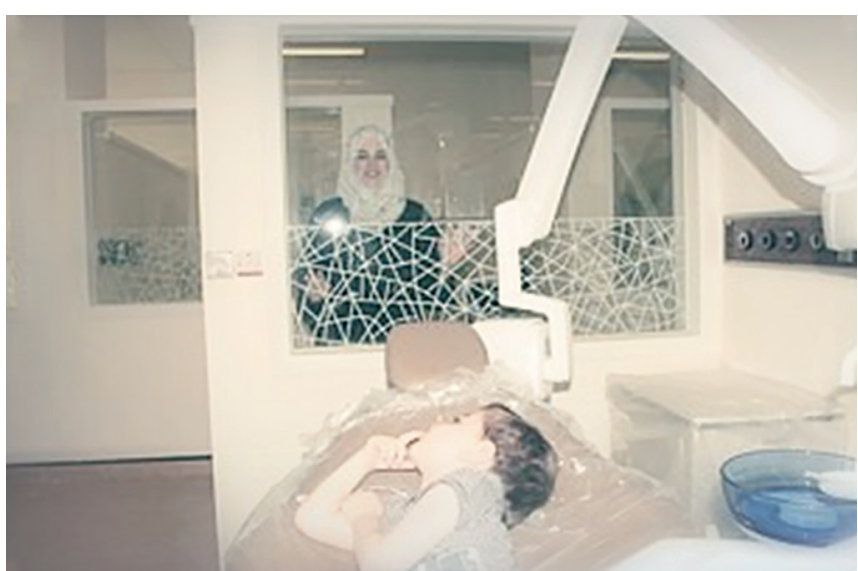

Fig. 4: As the child realizes the seriousness of the situation, he starts to act well

\section{REFERENCES}

1. Kantaputra PN, Chiewcharnvalijkit K, Wairatpanich K, Malikaew P, Aramrattana A. Children's attitudes toward behavior management techniques used by dentists. J Dent Child (Chic) 2007 Jan-Apr;74(1):4-9.

2. Wright GZ, Kupietzky A, editors. Behavior management in dentistry for children. Ames: John Wiley \& Sons; 2014.

3. American Academy on Pediatric Dentistry Clinical Affairs Committee-Behavior Management Subcommittee, American Academy on Pediatric Dentistry Council on Clinical Affairs. Guideline on behavior guidance for the pediatric dental patient. Pediatr Dent 2008-2009;30(7 Suppl):125-133.

4. Roberts JF, Curzon ME, Koch G, Martens LC. Review: Behaviour management techniques in paediatric dentistry. Eur Arch Paediatr Dent 2010 Aug;11(4):166-174.

5. Adair SM. Behavior management conference panel I reportRationale for behavior management techniques in pediatric dentistry. Pediatr Dent 2004 Mar-Apr;26(2):167-170.

6. Kuhn BR, Allen KD. Expanding child behavior management technology in pediatric dentistry: A behavioral science perspective. Pediatr Dent 1994 Jan-Feb;16(1):13-17.

7. Elango I, Baweja DK, Shivaprakash PK. Parental acceptance of pediatric behavior management techniques: a comparative study. J Indian Soc Pedod Prev Dent 2012 Dec;30(3):195-200.

8. McElroy CM. Dentistry for children. Calif Dent Assoc Trans 1895:85.

9. Eysenck HJ. Behavior therapy. In: Theoretical foundations of behavior therapy. Springer; 1987. pp. 3-35.

10. de Castro AM, de Oliveira FS, de Paiva Novaes MS, Araújo Ferreira DC. Behavior guidance techniques in pediatric dentistry: attitudes of parents of children with disabilities and without disabilities. Spec Care Dentist 2013 Sep-Oct;33(5):213-217.

11. Casamassimo PS, Wilson S, Gross L. Effects of changing US parenting styles on dental practice: perceptions of diplomates of the American Board of Pediatric Dentistry. Pediatr Dent 2002 Jan-Feb;24(1):18-22.

12. Frankl SN, Shiere FR, Fogels HR. Should the parent remain with the child in the dental operatory. J Dent Child 1962;29:150-163.

13. Bailey PM, Talbot A, Taylor PP. A comparison of maternal anxiety levels with anxiety levels manifested in the child dental patient. ASDC J Dent Child 1973 Jul-Aug;40(4):277-284. 
14. Marcum BK, Turner C, Courts FJ. Pediatric dentists' attitudes regarding parental presence during dental procedures. Pediatr Dent 1995 Nov-Dec;17(7):432-436.

15. Cox IC, Krikken JB, Veerkamp JS. Influence of parental presence on the child's perception of, and behaviour, during dental treatment. Eur Arch Paediatr Dent 2011 Aug;12(4):200-204.

16. Feigal RJ. Guiding and managing the child dental patient: Afresh look at old pedagogy. J Dent Educ 2001 Dec;65(12):1369-1377.

17. Fenlon WL, Dabbs AR, Curzon ME. Parental presence during treatment of the child patient: a study with British parents. Br Dent J 1993 Jan;174(1):23-28.

18. Kotsanos N, Coolidge T, Velonis D, Arapostathis KN. A form of 'parental presence/absence' (PPA) technique for the child patient with dental behaviour management problems. Eur Arch Paediatr Dent 2009 Jun;10(2):90-92.

19. Holst A, Schröder U, Ek L, Hallonsten AL, Crossner CG. Prediction of behavior management problems in children. Scand J Dent Res 1988;96(5):457-465.

20. Lewis TM, Law DB. Investigation of certain autonomic responses of children to a specific dental stress. J Am Dent Assoc 1958 Dec;57(6):769-777.

21. Abushal M, Adenubi JO. Attitudes of Saudi parents toward separation from their children during dental treatment. Saudi Dent J 2009 Jul;21(2):63-67.
22. Pinkham JR. An analysis of the phenomenon of increased parental participation during the child's dental experience. ASDC J Dent Child 1991 Nov-Dec;58(6):458-463.

23. Peretz B, Zadik D. Attitudes of parents towards their presence in the operatory during dental treatments to their children. J Clin Pediatr Dent 1998 Fall;23(1):27-30.

24. Kim JS, Boynton JR, Inglehart MR. Parents' presence in the operatory during their child's dental visit: a person-environmental fit analysis of parents' responses. Pediatr Dent 2012 Sep-Oct; 34(5):407-413.

25. Casamassimo PS, Fields HW Jr, McTigue DJ, Nowak A. Pediatric dentistry: infancy through adolescence. Philadelphia, PA: Elsevier Health Sciences; 2013.

26. Ripa, LR.; James, A. Management of dental behavior in children. In: Postgraduate dental handbook. Vol. 1. Littleton, MA: PSG Pubishing Co.; 1979.

27. Dean JA, Avery DR, McDonald RE. McDonald and avery dentistry for the child and adolescent. St Louis: Elsevier Health Sciences; 2010.

28. Fields H, Pinkham J. Videotape modeling of the child dental patient. J Dent Res 1976 Nov-Dec;55(6):958-963.

29. Melamed BG, Hawes RR, Heiby E, Glick J. Use of filmed modeling to reduce uncooperative behavior of children during dental treatment. J Dent Res 1975 Jul-Aug;54(4):797-801. 